\section{„Geruchsallergische" Schwangere}

다일 höhte Geruchsempfindlichkeit scheint ein typisches Phänomen der Frühschwangerschaft zu sein. Schon in den 30er Jahren wurde über derartige Beobachtungen publiziert, bis zu $70 \%$ der Schwangeren sind offensichtlich von diesem Phänomen betroffen. Die Geruchsüberempfindlichkeit beeinflusst sogar affektive Reaktionen bzw. das Verhalten im Alltag, so das Ergebnis einer neuen Studie, in der Schwangere und Nicht-Schwangere per Fragebogen verglichen wurden. Die Schwangeren fühlten sich häufiger durch Gerüche gestört, so dass sie beispielsweise gereizt reagierten, nicht richtig entspannen bzw. schlafen konnten und deshalb z. B. Fenster schlossen. Bei einer gleichzeitig erfragten Geräuschüberempfindlichkeit ergaben sich

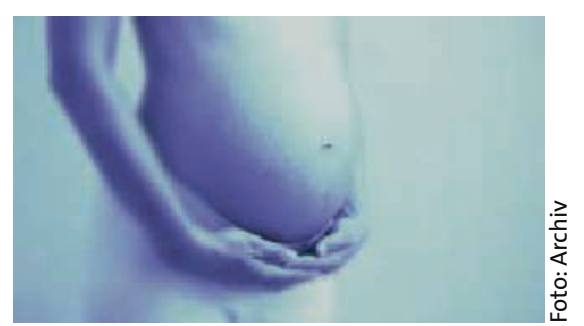

dagegen keine Unterschiede zwischen den beiden Frauengruppen. Die gesteigerten Aversionen und die damit verbundene negative affektive Reaktionslage werten die Autoren als Schutzmechanismus vor potenziell schädigenden Substanzen in der Frühschwangerschaft.

$b k$

Nordin S et al. Physiol Behav 2005; 84: 175-9

\title{
Krebs durch Stress - zumindest bei Mäusen
}

O b chronischer Stress Krebs auslösen kann, wird immer noch kontrovers diskutiert, einige epidemiologische Studien sprechen dafür. Dass chronischer Stress aber den Ausbruch einer Krebserkrankung beschleunigt, wurde jetzt an Nacktmäusen gezeigt. Sie wurden über 2 Wochen jeweils für eine Stunde in eine enge Röhre gesperrt und dort dem Geruch von Fuchsurin ausgesetzt - ein Reiz, der sie normalerweise zur Flucht vor diesem natürlichen Feind

\section{Neue Jobbörse online}

$\mathrm{D}$ ie Springer-Medizin-Verlage haben eine neue Internet-Stellenbörse für Mediziner ins Leben gerufen. Seit 21.

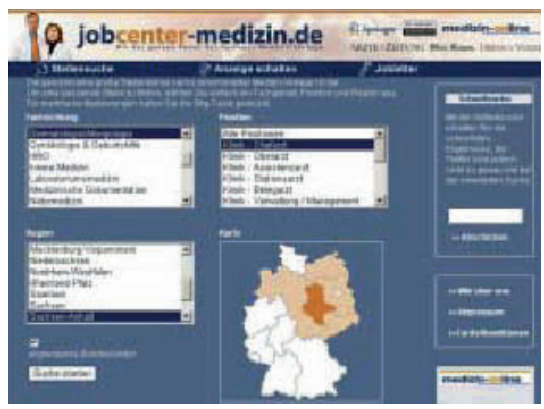

veranlasst. Es ist davon auszugehen, dass die Mäuse die Situation als stressig empfanden. Wurden sie dann - unter Beibehaltung der Stressreize - UV-Strahlung in Krebs erregender Intensität ausgesetzt, entwickelten sie signifikant schneller als ihre stressfrei gehaltenen Artgenossen einen Hautkrebs, meist vom Typ Plattenepithelkarzinom. $\quad b k$

Parker J et al. J Am Acad Dermatol 2004; 51: 919-22

März 2005 finden Stellenanbieter bei Jobcenter-Medizin eine reichenweitenstarke Plattform, um neue Mitarbeiter zu rekrutieren. Stellensuchenden bietet die Online-Jobbörse eine hohe Selektivität beim Suchergebnis und zusätzlich einen individuellen „Jobletter", der per E-Mail informiert, wenn neue Stellenausschreibungen vorliegen, die dem Suchprofil entsprechen. Die Jobbörse ist außerdem integraler Bestandteil auf allen SpringerOnline-Portalen.

$n z$

www.jobcenter-medizin.de

\section{Rot vom Weißwein}

— ine 56 jährige Patientin wurde wegen - Rosacea mit 0,1\%-iger Tacrolimussalbe behandelt. Nach etwa 2-wöchiger Therapiedauer ereignete sich während eines Abendempfangs, bei dem sie auch alkoholische Getränke genossen hatte, eine plötzliche Episode von Gesichtsröte. Die Patientin suchte darauf die Ambulanz des Genfer Universitätshospitals auf und stimmte schließlich einem Test zu, bei dem das Phänomen reproduziert werden sollte. Sie trug dazu eine Woche lang zweimal täglich $0,5 \mathrm{~g}$ der 0,1\%-igen Ta-
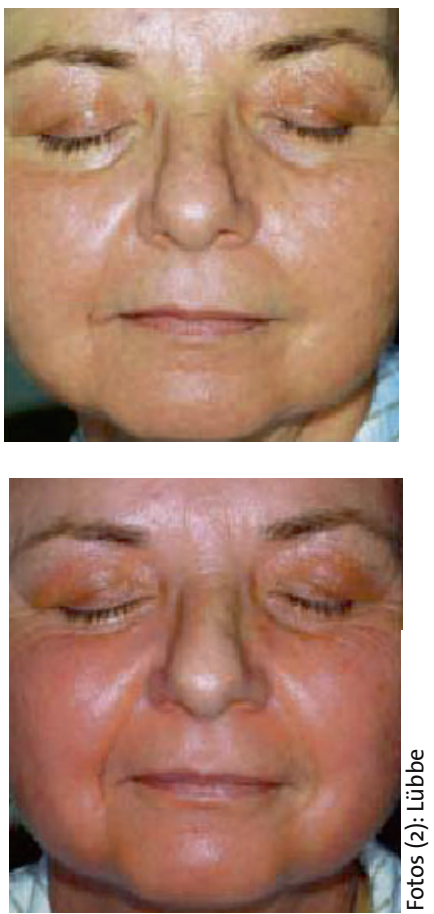

crolimussalbe auf das Gesicht auf und nahm dann in der Ambulanz 0,05 1 Weißwein zu sich. Das obere Bild zeigt das Gesicht der Patientin vor dem Genuss von Alkohol, das untere 12 Minuten danach. Das Erythem hielt etwa 45 Minuten lang an. Einen Monat nach Beendigung der Therapie konnte die Patientin wieder ohne Auftreten der unangenehmen Rötung alkoholische Getränke zu sich nehmen. Eine Alkoholintoleranz tritt bei etwa 7\% der erwachsenen Patienten auf, die topische Tacrolimuspräparate verwenden.

Lübbe J et al. New Engl J Med 2004; 351: 2740 